\title{
Tantangan Adopsi Agile di Perguruan Tinggi di Indonesia
}

\author{
(Challenges of Agile Adoption in Higher Education in \\ Indonesia)
}

\author{
Sujono Sujono', Mukhamad Andri Setiawan ${ }^{2}$, Kholid Haryono ${ }^{3}$ \\ ${ }^{1,2,3}$ Magister Teknik Informatika, Universitas Islam Indonesia, Yogyakarta \\ ${ }^{1}$ sujono@students.uii.ac.id \\ 2andri.setiawan@ui.ac.id \\ ${ }^{3}$ kholid.haryonodui.ac.id
}

\begin{abstract}
Abstrak - Tingkat kesuksesan dalam pengembangan proyek perangkat lunak di berbagai negara masih rendah. Berdasarkan data yang ditemukan, di Amerika Serikat dan Eropa masih berkisar antara 16\%-31\%, di Afrika Selatan 34\%, dan di Indonesia sebesar 27\%. Agile merupakan pendekatan yang relatif baru dalam pengembangan perangkat lunak. Banyak organisasi telah mengadopsi Agile di semua atau beberapa proyek mereka. Temuan penelitian di berbagai industri dan negara, menunjukkan bahwa metode Agile memiliki dampak positif pada dimensi keberhasilan proyek. Namun upaya untuk melakukan adopsi Agile tidak sepenuhnya berjalan lancar, ditemukan berbagai tantangan yang mempengaruhi kesuksesannya. Penelitian ini dilakukan dengan tujuan untuk mengindentifikasi tantangan yang dihadapi dalam adopsi Agile di Perguruan Tinggi di Indonesia dengan menggunakan teori Scrum Adoption Challenges Detection Model (SACDM). Penelitian kuantitatif berbasis survei dan wawancara ini dilakukan di Badan Sistem Informasi (BSI), Universitas Islam Indonesia. Responden yang mengisi kuesioner sebanyak 41 orang yaitu Development (51,2\%), Operational (22\%), Product Owner (14,6\%), dan Scrum Master dan Manajemen BSI (12,2\%). Analisis data dilakukan dengan menggunakan uji statistik yaitu uji validitas dan analysis of variance. Berdasarkan hasil analisis, telah teridentifikasi 12 variabel tantangan dalam adopsi Agile dalam penelitian ini.
\end{abstract}

Kata-kata kunci: Tantangan adopsi Agile, Scrum, SACDM, BSI UII

Abstract - The level of success in developing software projects in various countries is still low. Based on the data found, in the United States and Europe still ranges between $16 \%-31 \%$, in South Africa 34\%, and in Indonesia by $27 \%$. Agile is a relatively new approach in software development. Many organizations have adopted Agile in all or some of their projects. Research findings in various industries and countries, show that the Agile method has a positive impact on the dimensions of project success. However, the efforts to adopt Agile did not fully go smoothly, found various challenges that affected his success. This study was conducted with the aim of identifying the challenges faced in Agile adoption in Higher Education in Indonesia using the Scrum Adoption Challenges Detection Model (SACDM) theory. This survey and interview-based quantitative research was conducted at the Information Systems Board, Universitas Islam Indonesia. Respondents who filled in the questionnaire were 41 people, namely Development (51.2\%), Operational (22\%), Product Owner (14.6\%), and Scrum Masters and Management of BSI (12.2\%). Data analysis was performed using a statistical test that is the validity test and analysis of variance. Based on the analysis results, 12 challenge variables in the adoption of Agile have been identified in this study.

\section{Keywords: Challenges of Agile Adoption, Scrum, SACDM,} Information System Board of UII

\section{PENDAHULUAN}

Tingkat kesuksesan dalam pengembangan proyek sistem informasi/perangkat lunak di berbagai negara masih rendah. Heeks [1] memaparkan bahwa semua proyek e-government di negara berkembang sebesar $15 \%$ yang berhasil, $35 \%$ mengalami kegagalan total dan $50 \%$ mengalami kegagalan parsial, sehingga perlu dilakukan identifikasi terhadap layanan yang sukses. The Standish Group International [2], [3] dalam Chaos Report dari tahun 1994 sampai 2015, di mana mayoritas penelitiannya dilakukan di Amerika Serikat dan Eropa, menjelaskan bahwa tingkat kesuksesan proyek sistem informasi masih berkisar antara 16\% sampai dengan $31 \%$. Joseph [4] dalam penelitian terhadap proyek perangkat lunak di Afrika Selatan tahun 2013 menjelaskan bahwa sebesar $34 \%$ berhasil, namun 
sebesar 66\% mengalami kegagalan dan menghadapi tantangan. Sementara itu, Apriyanto \& Putro [5] dalam penelitiannya terhadap 110 proyek sistem informasi di Indonesia, ditemukan bahwa proyek sistem informasi yang selesai berhasil sebesar $27 \%$, lainnya sebesar $55 \%$ bermasalah, dan $18 \%$ dibatalkan.

Agile adalah kemampuan untuk membuat dan menanggapi perubahan dalam lingkungan yang tidak pasti. Agile Development Methods merupakan istilah untuk set kerangka kerja dalam pengembangan perangkat lunak yang didasarkan pada nilai-nilai dan prinsip-prinsip yang dinyatakan dalam Manifesto untuk pengembangan Agile. Nilai-nilai dan prinsip-prinsip memberikan panduan tentang cara membuat dan menanggapi perubahan dan bagaimana menangani ketidakpastian [6]. Agile merupakan pendekatan yang relatif baru dalam pengembangan perangkat lunak [7]. Banyak organisasi terkemuka telah mengadopsi Agile di semua atau beberapa proyek mereka [8]. Agile menjadi semakin populer, sehingga banyak organisasi yang berusaha mengadopsi pengembangan perangkat lunak Agile tersebut [9]. Hal ini didorong oleh adanya kebutuhan akan perlunya solusi perangkat lunak yang lebih baik, lebih cepat dan hemat biaya, dan pada saat yang sama juga memberikan tingkat kepuasan kerja karyawan yang tinggi [7].

Dalam penelitian dengan sampel data dari 1002 proyek di berbagai industri dan negara, telah dilakukan pengujian terhadap efek penggunaan Agile dalam organisasi pada dua dimensi keberhasilan proyek yaitu efisiensi dan kepuasan pemangku kepentingan secara keseluruhan terhadap tujuan organisasi. Temuan penelitian menunjukkan bahwa metode Agile memiliki dampak positif pada kedua dimensi keberhasilan proyek tersebut [10]. Temuan lain oleh Standish Group tahun 2015 mengidentifikasi dua faktor yang menciptakan kesuksesan adalah proses Agile dan proyek-proyek kecil.
Proyek-proyek kecil yang menggunakan proses Agile hanya memiliki tingkat kegagalan 4\% [3].

Chaos Report memberikan pandangan statistik terkait hasil chaos proyek sistem informasi, dari jumlah total proyek perangkat lunak lebih dari 10.000, hasil untuk semua proyek menunjukkan bahwa proyek Agile memiliki hampir empat kali tingkat keberhasilannya dibandingkan dengan Waterfall, sedangkan proyek Waterfall memiliki tiga kali tingkat kegagalan dibanding Agile. Sebagaimana tersebut dalam Gambar 1, hasil keseluruhan jelas menunjukkan bahwa proyek Agile lebih baik dibandingkan dengan Waterfall pada proyek berskala besar, menengah, dan kecil [3].

Berdasarkan studi literatur, upaya untuk melakukan adopsi Agile di berbagai organisasi atau perusahaan di beberapa negara tidak sepenuhnya berjalan lancar. Ditemukan berbagai tantangan yang mempengaruhi kesuksesan dalam adopsi Agile. Di lembaga keuangan di Kosovo, tantangan yang dihadapi antara lain memiliki dukungan dari manajemen dan ketrampilan untuk metodologi, anggaran, dan orang-orang yang mengenali dan bersedia untuk melompat dalam mode Agile [11]. Dalam tim multidisiplin di Brasil, dipaparkan bahwa komunikasi langsung menyebabkan gangguan konstan pada proses pembangunan, jumlah komunikasi informal yang berlebihan, sentralisasi informasi dalam anggota tertentu merupakan tantangan dalam adopsi Agile [12]. Penelitian pada perusahaan E-Commerce di Amerika Serikat, tantangannya adalah kurangnya informasi tentang Scrum dan kurangnya izin dari perusahaan [13]. Sementara itu, penelitian pada Entitas Pemerintah di Uni Emirat Arab yang menjadi tantangan yaitu Kehilangan peran Master Agile, Tim terlalu bersemangat, Tidak adanya Pilot Project, Belum ada karyawan yang berpengalaman dengan metode Agile, Tekanan kerja, Manajemen atas tidak mudah diyakinkan berinvestasi dengan metode baru, Sistem birokrasi pemerintahan, dan Persyaratan dokumentasi [7].

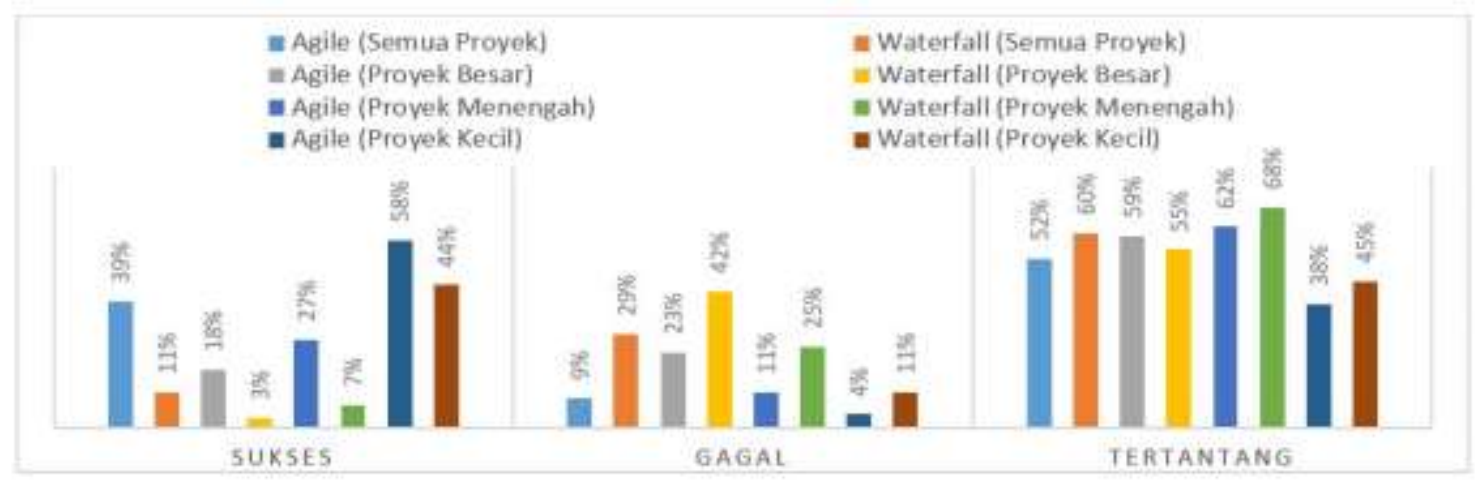

Gambar 1. Perbandingan proyek sistem informasi dengan agile dan waterfall 
Sebagaimana paparan di atas, tantangan dalam melakukan adopsi Agile di setiap organisasi/perusahaan di berbagai negara ditemukan dengan berbagai variasi. Oleh karena itu, penelitian ini dilakukan untuk mengidentifikasi tantangan adopsi Agile di Perguruan Tinggi di Indonesia, dengan studi kasus di Badan Sistem Informasi Universitas Islam Indonesia (BSI UII). Diharapkan hasil dari penelitian ini dapat menjadi referensi bagi institusi pendidikan khususnya perguruan tinggi dalam melakukan adopsi Agile di institusinya.

\section{METODE}

Penelitian ini merupakan penelitian kuantitatif berbasis survei dan wawancara dengan menggunakan teori SACDM. Teori ini merupakan model yang diadaptasi dari teori Diffusion of Innovation (DOI) dan kerangka konseptual teknologi berorientasi obyek [14] yang terdiri dari empat konstruk sebagaimana Gambar 2.

\section{A. Instrumen}

Penelitian ini menggunakan dua jenis data yaitu data primer dan data sekunder. Data primer merupakan data hasil observasi di lokasi penelitian seperti data survei dan wawancara, sedangkan data sekunder adalah data dari berbagai literatur baik jurnal ilmiah, buku, hasil penelitian, dan materi yang berkaitan dengan topik penelitian.

\section{B. Responden}

Responden dalam penelitian ini berasal dari berbagai kelompok fungsional di organisasi yaitu Scrum Master (SM), Product Owner (PO), Team Member (Development dan Operational), dan Manajemen BSI UII. Jumlah responden adalah 41 responden (laki-laki sebesar 82,9\%; perempuan sebesar 17,1\%) dengan rincian yaitu Development: 21 orang $(51,2 \%)$, Operational: 9 orang (22\%), PO: 6 orang (14,6\%), dan $S M$ dan Manajemen BSI UII: 5 orang $(12,2 \%)$.

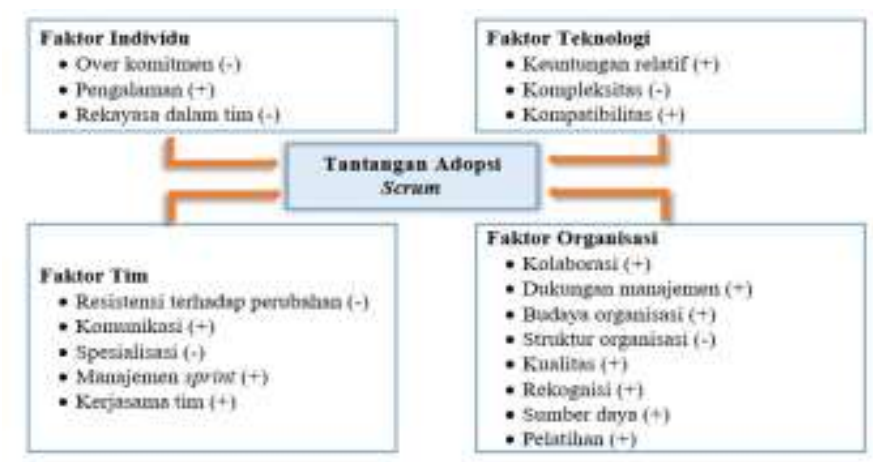

Gambar 2. Kerangka kerja konseptual
Responden berdasarkan usia [15], didominasi oleh generasi Y (millennials): 90,2\%, lainnya: 9,8\% yaitu generasi X. Sementara itu, responden menurut kategori pendidikan yaitu S1 (70,7\%), S2 (12,2\%), S3 (2,4\%), Diploma (4,9\%), dan SMA/SMK (9,8\%).

Berkaitan dengan pelaksanaan distribusi kuesioner penelitian, untuk memastikan bahwa kuesioner mendapatkan respon yang akurat, karena kuesioner cukup luas dengan jumlah pertanyaan yang banyak, maka kuesioner dibagikan langsung di lokasi penelitian pada akhir Desember 2019-pertengahan Januari 2020.

\section{Analisis Data}

Analisis data dilakukan terhadap data kuantitatif berbasis kuesioner dengan menggunakan uji statistik yaitu uji validitas dan analysis of variance. Uji validitas dilakukan dengan korelasi bivariate antara masingmasing skor indikator dengan total skor konstruk. Hasil dari pelaksanaan uji validitas diperoleh nilai signifikan yang menunjukkan bahwa indikator pertanyaan adalah valid. Analysis of variance dilakukan untuk melihat hubungan antara variabel independen dengan variabel dependen [16]. Mean per variabel atau kelompok dalam analysis of variance dihitung dari jumlah seluruh nilai data responden dibagi jumlah seluruh responden dengan rumus seperti pada persamaan 1 .

$\bar{X}=\frac{X 1+X 2+\cdots+X n}{n}$

Keterangan:

$\bar{X}=$ Mean per variabel atau kelompok

$\mathrm{x}=$ Nilai data responden

$\mathrm{n}=$ Jumlah seluruh responden

\section{HASIL DAN PEMBAHASAN}

\section{A. Isian Data Responden}

Data responden berbasis kuesioner dalam penelitian ini telah dilakukan rekapitulasi berdasarkan jumlah isian penilaian dari responden. Isian penilaian responden tersebut meliputi skor nilai antara 1-5 sebagaimana Tabel I.

\section{B. Analisis Data}

\section{1) Uji Validitas}

Uji validitas dilakukan dengan korelasi bivariate antara masing-masing skor indikator dengan total skor konstruk. Hasil pengukuran berdasarkan uji validitas yang telah dilakukan menunjukkan bahwa semua indikator memperoleh hasil signifikan pada level 0.01 yang berarti bahwa indikator pertanyaan adalah valid sebagaimana Tabel II. 
TABEL I

REKAPITULASI ISIAN DATA RESPONDEN

\begin{tabular}{|c|c|c|c|c|c|c|c|c|c|c|c|c|c|c|c|}
\hline \multirow{2}{*}{ No } & \multirow{2}{*}{ Variabel } & \multirow{2}{*}{ Indikator } & \multicolumn{5}{|c|}{ Jumlah Nilai Kuesioner } & \multirow{2}{*}{ No } & \multirow{2}{*}{ Variabel } & \multirow{2}{*}{ Indikator } & \multicolumn{5}{|c|}{ Jumlah Nilai Kuesioner } \\
\hline & & & 1 & 2 & 3 & 4 & 5 & & & & 1 & 2 & 3 & 4 & 5 \\
\hline \multirow[t]{2}{*}{1} & Over komitmen [17] & FIN_A1 & 0 & 12 & 18 & 9 & 2 & 12 & Sumber daya [18] & FOrg_D1 & 0 & 2 & 11 & 20 & 8 \\
\hline & & FIN_A2 & 1 & 5 & 8 & 21 & 6 & & & FOrg_D2 & 0 & 1 & 9 & 23 & 8 \\
\hline \multirow[t]{2}{*}{2} & Rekayasa dalam tim [19] & FIN_B1 & 0 & 2 & 16 & 18 & 5 & 13 & Kolaborasi [18] & FOrg_E1 & 0 & 0 & 0 & 22 & 19 \\
\hline & & FIN_B2 & 0 & 2 & 6 & 22 & 11 & & & FOrg_E2 & 0 & 0 & 0 & 28 & 13 \\
\hline \multirow[t]{3}{*}{3} & Pengalaman [20] & FIN_C1 & 8 & 0 & 16 & 0 & 17 & & & FOrg_E3 & 0 & 0 & 1 & 21 & 19 \\
\hline & & FIN_C2 & 12 & 0 & 28 & 0 & 1 & 14 & Dukungan manajemen & FOrg_F1 & 0 & 0 & 1 & 26 & 14 \\
\hline & & FIN_C3 & 13 & 0 & 19 & 0 & 9 & & {$[18],[21]$} & FOrg_F2 & 0 & 1 & 1 & 29 & 10 \\
\hline \multirow[t]{2}{*}{4} & Komunikasi [14] & FTim_A1 & 0 & 0 & 1 & 22 & 18 & & & FOrg_F3 & 0 & 1 & 15 & 21 & 4 \\
\hline & & FTim_A2 & 0 & 0 & 1 & 21 & 19 & & & FOrg_F4 & 0 & 1 & 15 & 19 & 6 \\
\hline \multirow[t]{2}{*}{5} & Kerjasama tim [14] & FTim_B1 & 0 & 0 & 0 & 28 & 13 & & & FOrg_F5 & 0 & 1 & 8 & 27 & 5 \\
\hline & & FTim_B2 & 0 & 0 & 3 & 26 & 12 & & & FOrg_F6 & 0 & 2 & 12 & 20 & 7 \\
\hline 6 & Spesialisasi [22] & FTim_C & 0 & 2 & 7 & 19 & 13 & 15 & Budaya organisasi [14] & FOrg_G1 & 0 & 1 & 16 & 20 & 4 \\
\hline \multirow[t]{2}{*}{7} & Manajemen sprint [20] & FTim_D1 & 0 & 0 & 2 & 29 & 10 & & & FOrg_G1 & 0 & 3 & 11 & 25 & 2 \\
\hline & & FTim_D2 & 0 & 0 & 3 & 26 & 12 & 16 & Struktur organisasi [21] & FOrg_H & 1 & 1 & 15 & 21 & 3 \\
\hline \multirow[t]{3}{*}{8} & Resistensi terhadap perubahan & FTim_E1 & 0 & 0 & 5 & 23 & 13 & 17 & Keuntungan relatif [21] & FTek_A1 & 0 & 1 & 8 & 30 & 2 \\
\hline & {$[18]$} & FTim_E2 & 1 & 0 & 2 & 27 & 11 & & & FTek_A2 & 0 & 0 & 3 & 35 & 3 \\
\hline & & FTim_E3 & 0 & 2 & 15 & 18 & 6 & & & FTek_A3 & 0 & 1 & 7 & 29 & 4 \\
\hline \multirow[t]{2}{*}{9} & Pelatihan [23] & FOrg_A1 & 0 & 0 & 2 & 27 & 12 & & & FTek_A4 & 0 & 2 & 8 & 28 & 3 \\
\hline & & FOrg_A2 & 0 & 1 & 5 & 29 & 6 & & & FTek_A5 & 0 & 0 & 4 & 34 & 3 \\
\hline \multirow[t]{2}{*}{10} & Rekognisi [20] & FOrg_B1 & 0 & 1 & 5 & 21 & 14 & 18 & Kompleksitas [14] & FTek_B1 & 1 & 1 & 18 & 20 & 1 \\
\hline & & FOrg_B2 & 0 & 1 & 20 & 17 & 3 & & & FTek_B2 & 0 & 2 & 11 & 24 & 4 \\
\hline \multirow[t]{4}{*}{11} & Kualitas [21] & FOrg_C1 & 0 & 1 & 6 & 30 & 4 & 19 & Kompatibilitas [21] & FTek_C1 & 0 & 7 & 16 & 17 & 1 \\
\hline & & FOrg_C2 & 0 & 1 & 8 & 28 & 4 & & & FTek_C2 & 0 & 1 & 14 & 23 & 3 \\
\hline & & FOrg_C3 & 0 & 0 & 6 & 32 & 3 & & & FTek_C3 & 0 & 1 & 16 & 21 & 3 \\
\hline & & FOrg_C4 & 0 & 0 & 6 & 25 & 10 & & & & & & & & \\
\hline
\end{tabular}

TABEL II

PENGUKURAN VALIDITAS DALAM ADOPSI AGILE

\begin{tabular}{|c|c|c|c|c|c|c|c|c|c|}
\hline No & Variabel & $\begin{array}{l}\text { Jml per- } \\
\text { tanyaan }\end{array}$ & Indikator & $\begin{array}{l}\text { Pearson } \\
\text { Correlation }\end{array}$ & No & Variabel & $\begin{array}{l}\text { Jml per- } \\
\text { tanyaan }\end{array}$ & Indikator & $\begin{array}{l}\text { Pearson } \\
\text { Correlation }\end{array}$ \\
\hline \multirow[t]{2}{*}{1} & \multirow[t]{2}{*}{ Over komitmen [17] } & \multirow[t]{2}{*}{2} & FIN_A1 & $0,793 * *$ & \multirow[t]{2}{*}{12} & \multirow[t]{2}{*}{ Sumber daya [18] } & \multirow[t]{2}{*}{2} & FOrg_D1 & $0,858 * *$ \\
\hline & & & FIN_A2 2 & $0,845^{* *}$ & & & & FOrg_D2 & $0,820 * *$ \\
\hline \multirow[t]{2}{*}{2} & \multirow[t]{2}{*}{ Rekayasa dalam tim [19] } & \multirow[t]{2}{*}{2} & FIN_B1 & $0,788 * *$ & \multirow[t]{3}{*}{13} & \multirow[t]{3}{*}{ Kolaborasi [18] } & \multirow[t]{3}{*}{3} & FOrg_E1 & $0,898 * *$ \\
\hline & & & FIN_B2 & $0,802 * *$ & & & & FOrg_E2 & $0,773 * *$ \\
\hline \multirow[t]{3}{*}{3} & \multirow[t]{3}{*}{ Pengalaman [20] } & \multirow[t]{3}{*}{3} & FIN_C1 & $0,804 * *$ & & & & FOrg_E3 & $0,901 * *$ \\
\hline & & & FIN_C2 & $0,827 * *$ & \multirow[t]{6}{*}{14} & \multirow{6}{*}{$\begin{array}{l}\text { Dukungan manajemen } \\
{[18],[21]}\end{array}$} & \multirow[t]{6}{*}{6} & FOrg_F1 & $0,431 * *$ \\
\hline & & & FIN_C3 & $0,853 * *$ & & & & FOrg_F2 & $0,574 * *$ \\
\hline \multirow[t]{2}{*}{4} & \multirow[t]{2}{*}{ Komunikasi [14] } & \multirow[t]{2}{*}{2} & FTim_A1 & $0,924 * *$ & & & & FOrg_F3 & $0,812 * *$ \\
\hline & & & FTim_A2 & $0,925 * *$ & & & & FOrg_F4 & $0,823 * *$ \\
\hline \multirow[t]{2}{*}{5} & \multirow{2}{*}{ Kerjasama tim [14] } & \multirow[t]{2}{*}{2} & FTim_B1 & $0,795 * *$ & & & & FOrg_F5 & $0,793 * *$ \\
\hline & & & FTim_B2 & $0,866^{* *}$ & & & & FOrg_F6 & $0,645 * *$ \\
\hline 6 & Spesialisasi [22] & 1 & FTim_C & 1 & 15 & Budaya organisasi [14] & 2 & FOrg_G1 & $0,822 * *$ \\
\hline \multirow[t]{2}{*}{7} & \multirow[t]{2}{*}{ Manajemen sprint [20] } & \multirow[t]{2}{*}{2} & FTim_D1 & $0,915^{* *}$ & & & & FOrg_G1 & $0,825 * *$ \\
\hline & & & FTim_D2 & $0,932 * *$ & 16 & Struktur organisasi [21] & 1 & FOrg_H & 1 \\
\hline \multirow[t]{3}{*}{8} & \multirow{3}{*}{$\begin{array}{l}\text { Resistensi terhadap perubahan } \\
{[18]}\end{array}$} & \multirow[t]{3}{*}{3} & FTim_E1 & $0,799 * *$ & 17 & Keuntungan relatif [21] & 5 & FTek_A1 & $0,729 * *$ \\
\hline & & & FTim_E2 & $0,859 * *$ & & & & FTek_A2 & $0,839 * *$ \\
\hline & & & FTim_E3 & $0,835 * *$ & & & & FTek_A3 & $0,775 * *$ \\
\hline \multirow[t]{2}{*}{9} & Pelatihan [23] & 2 & FOrg_A1 & $0,785^{* *} *$ & & & & FTek_A4 & $0,804 * *$ \\
\hline & & & FOrg_A2 & $0,839 * *$ & & & & FTek_A5 & $0,671 * *$ \\
\hline 10 & Rekognisi [20] & 2 & FOrg_B1 & $0,801 * *$ & 18 & Kompleksitas [14] & 2 & FTek_B1 & $0,895 * *$ \\
\hline & & & FOrg_B2 & $0,755^{* *}$ & & & & FTek_B2 & $0,894 * *$ \\
\hline 11 & Kualitas [21] & 4 & FOrg_C1 & $0,767 * *$ & 19 & Kompatibilitas [21] & 3 & FTek_C1 & $0,682 * *$ \\
\hline & & & FOrg_C2 & $0,741 * *$ & & & & FTek_C2 & $0,850 * *$ \\
\hline & & & FOrg_C3 & $0,777 * *$ & & & & FTek_C3 & $0,885 * *$ \\
\hline & & & FOrg_C4 & $0,756^{* * *}$ & & & & & \\
\hline
\end{tabular}

\section{2) Analysis of Variance}

Analysis of variance dilakukan untuk melihat hubungan antara variabel independen dengan variabel dependen. Analysis of variance dilakukan pada empat konstruk yaitu faktor individu, faktor tim, faktor organisasi, dan faktor teknologi dengan hasil sebagaimana Tabel III. 
TABEL III

ANALYSIS OF VARIANCE DALAM ADOPSI AGILE

\begin{tabular}{|c|c|c|c|c|c|c|c|c|c|c|c|c|c|c|c|}
\hline \multirow{2}{*}{ No } & \multirow{2}{*}{ Variabel } & \multirow{2}{*}{ Kode } & \multicolumn{4}{|c|}{ Mean Kelompok } & \multirow{2}{*}{$\begin{array}{l}\text { Mean per } \\
\text { Variabel }\end{array}$} & \multirow{2}{*}{\multicolumn{2}{|c|}{ No Variabel }} & \multirow[t]{2}{*}{ Kode } & \multicolumn{4}{|c|}{ Mean Kelompok } & \multirow{2}{*}{$\begin{array}{l}\text { Mean per } \\
\text { Variabel }\end{array}$} \\
\hline & & & $\overline{\text { Dev }}$ & Ops & PO & SM_Mg & & & & & Dev & Ops & PO & SM_Mg & \\
\hline$\overline{1}$ & Over komitmen & FIN_A & 3,07 & 3,67 & 3,75 & 3,30 & 3,33 & 11 & Kualitas & FOrg_C & 4,01 & 3,70 & 3,88 & 4,20 & 3,95 \\
\hline 2 & Rekayasa dalam tim & FIN_B & 3,71 & 3,78 & 3,84 & 4,40 & 3,83 & 12 & Sumber daya & FOrg_D & 3,96 & 3,50 & 3,67 & 4,50 & 3,88 \\
\hline 3 & Pengalaman & FIN_C & 2,62 & 2,41 & 4,00 & 3,67 & 2,90 & 13 & Kolaborasi & FOrg_E & 4,38 & 4,22 & 4,44 & 4,80 & 4,41 \\
\hline 4 & Komunikasi & FTim_A & 4,43 & 4,29 & 4,56 & 4,42 & 4,43 & 14 & Dukungan manajemen & FOrg_F & 3,81 & 3,95 & 3,81 & 4,53 & 3,93 \\
\hline 5 & Kerjasama tim & FTim_B & 4,27 & 4,17 & 4,44 & 4,17 & 4,27 & 15 & Budaya organisasi & FOrg_G & 3,62 & 3,56 & 3,50 & 4,10 & 3,65 \\
\hline 6 & Spesialisasi & FTim_C & 3,95 & 4,22 & 3,83 & 4,40 & 4,05 & 16 & Struktur organisasi & FOrg_H & 3,48 & 3,56 & 3,50 & 4,20 & 3,59 \\
\hline 7 & Manajemen sprint & FTim_D & 4,21 & 4,19 & 3,84 & 4,50 & 4,21 & 17 & Keuntungan relatif & FTek_A & 3,86 & 3,93 & 3,83 & 3,96 & 3,89 \\
\hline 8 & $\begin{array}{l}\text { Resistensi terhadap } \\
\text { perubahan }\end{array}$ & FTim_E & 4,01 & 3,94 & 4,04 & 3,67 & 4,01 & 18 & Kompleksitas & FTek_B & 3,83 & 3,78 & 3,83 & 3,90 & 3,60 \\
\hline 9 & Pelatihan & FOrg_A & 4,00 & 4,11 & 4,17 & 4,50 & 4,11 & 19 & Kompatibilitas & FTek_C & 3,57 & 3,41 & 3,17 & 4,07 & 3,53 \\
\hline 10 & Rekognisi & FOrg_B & 3,88 & 3,56 & 4,00 & 4,10 & 3,86 & & & & & & & & \\
\hline
\end{tabular}

\section{a. Faktor individu}

Pada faktor individu, rata-rata terbesar yaitu pada variabel rekayasa dalam tim $(3,83)$ dengan skor penilaian 1-5, dan rata-rata terendah pada variabel pengalaman. Ketiga variabel tersebut nilainya masih berada di bawah 4.00 dan salah satu variabel memperoleh nilai rata-rata terendah di antara sembilan belas variabel yang lain. Berikut gambaran yang lebih komprehensif pada faktor individu berdasarkan wawancara dengan responden:

- Over komitmen: Over komitmen didefinisikan sebagai terus menugaskan sumber daya untuk proyek-proyek yang menunjukkan tanda-tanda kegagalan. Berdasarkan wawancara yang dilakukan, ditemukan beberapa proyek perangkat lunak yang penyelesaiannya telah melewati estimasi waktu yang ditetapkan. Keputusan atas keberlanjutan proyek tersebut merupakan tanggung jawab manajemen BSI. Responden memberikan gambaran dalam pengembangan UIIPrint yang memiliki tujuan yaitu perubahan culture dari end user (mahasiswa, dosen, dan karyawan). Penggunaan UIIPrint oleh end user pada awalnya tidak ada. Kemudian manajemen BSI melakukan analisis SWOT, memberi solusi yang terukur, sebelum memutuskan proyek yang dievaluasi akan dilanjutkan atau tidak.

- Rekayasa dalam tim: Rekayasa dalam tim berhubungan dengan pemahaman tim dalam menangkap kebutuhan pengguna. Dari hasil wawancara didapatkan bagaimana strategi tim pengembangan dalam melakukan koordinasi dengan pengguna untuk dapat menangkap kebutuhan pengguna agar sesuai dengan keinginannya. Strategi dari pengembang yaitu melakukan pertemuan formal seperti rapat koordinasi antara tim pengembang, pengguna beserta pimpinannya, serta pertemuan informal yaitu tim pengembang menyediakan waktu yang terjadwal selama dua hari dalam sepekan dengan standby di tempat pengguna. Pada rekayasa dalam tim, ditemukan keterlibatan secara langsung antara tim pengembangan dengan pengguna.

- Pengalaman: Pengalaman anggota tim, baik dalam keterlibatannya di pengembangan perangkat lunak, dalam menggunakan Agile/Scrum, maupun durasi waktu bekerja di BSI UII, telah mendapatkan perhatian dari manajemen organisasi. Antisipasi yang diterapkan oleh organisasi untuk meningkatkan kompetensi dan menambah pengalaman yang menjadi komitmen manajemen antara lain: (a) beberapa anggota tim dikirim ke acara-acara Scrum di luar organisasi, (b) organisasi mengadakan pelatihan Scrum secara internal dengan menghadirkan pembicara dari luar organisasi, (c) anggota tim yang telah mengikuti acara Scrum dari luar organisasi kemudian melakukan transfer knowledge kepada anggota tim yang lain, (d) organisasi melakukan pendataan kepada anggota tim terkait pelatihan apa saja yang diperlukan untuk meningkatkan kompetensi mereka, (e) peningkatan literasi anggota tim terhadap Scrum Guide. Hal ini sejalan dengan core BSI UII sebagai organisasi pendidikan yaitu mendidik dan mencerdaskan orang termasuk pegawai pemula (rekrutmen fresh graduate).

b. Faktor tim

Pada faktor tim, nilai rata-rata yang diperoleh kelima variabel sudah berada di atas 4,00 yang mengindikasikan bahwa kelima variabel tersebut sudah tidak perlu mendapatkan perhatian lebih dalam melakukan adopsi Agile. Nilai rata-rata tertinggi yaitu 
pada variabel komunikasi dengan skor 4,43 dan merupakan skor tertinggi dari seluruh variabel. Hal ini menunjukkan bahwa anggota tim dapat melakukan komunikasi secara formal maupun informal dengan baik, serta terjadi interaksi untuk saling bertukar gagasan dengan anggota tim lainnya.

Berikut adalah catatan penting berdasarkan wawancara terkait variabel komunikasi yang memperoleh skor tertinggi sebagai berikut: (1) Komunikasi yang terjalin dengan baik antar anggota tim melalui berbagai media yang disediakan oleh organisasi seperti melalui Slack, menjadikan pekerjaan yang sebelumnya tersembunyi (kurang jelas) menjadi kelihatan semua. (2) Daily Scrum merupakan media komunikasi yang sangat efektif bagi anggota tim untuk berbagi informasi pekerjaan. Dalam daily Scrum dengan durasi waktu maksimal 15 menit, antar anggota tim terjalin komunikasi secara terbuka. Selain itu, daily Scrum menjadikan kualitas komunikasi menjadi meningkat dan terjadi transfer knowledge antar anggota tim. (3) Desain tempat kerja yang disediakan oleh organisasi dengan posisi tempat duduk yang saling berhadap-hadapan antar anggota tim dengan ruang yang terbuka sebagaimana Gambar 3, memudahkan anggota tim untuk saling berkomunikasi secara langsung.

Pengelolaan informasi telah dilakukan dengan baik yaitu melalui penyediaan software yang sesuai dan peningkatan kualitas software juga dilakukan oleh organisasi untuk memfasilitasi agar komunikasi terbuka antar anggota tim selalu terjalin. BSI UII memakai Confluence sebagai knowledge manajemen sistem dan Jira yang digunakan untuk manajemen pekerjaan sebagai pengganti Trello yang tidak mampu memenuhi aliran informasi di organisasi. (5) Komunikasi di Scrum dapat dilakukan secara informal karena masing-masing anggota tim Scrum memiliki kedudukan yang sejajar, tidak ada atasan dan bawahan yang terkadang menjadikan komunikasi informal jarang terjadi.

Sementara itu, kerjasama tim untuk menyelesaikan tugas dan mencapai tujuan bersama juga telah terjalin dengan baik. Anggota tim merasakan bahwa kerjasama tim lebih disukai dalam kelompok dibandingkan dengan mengerjakan sendiri. Terkait

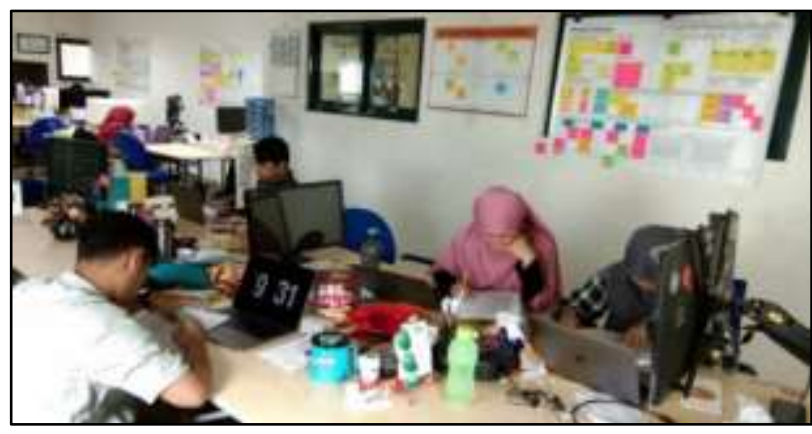

Gambar 3. Desain Tempat Kerja di BSI UII

dengan spesialisasi yang didefinisikan sebagai proses seorang individu yang memiliki tingkat pengetahuan dan keterampilan yang tinggi dalam bidang minat keahlian, responden menyatakan mudah dalam melakukan komunikasi, koordinasi, dan bekerjasama dengan anggota tim yang memiliki lebih banyak pengalaman dan kemampuan yang lebih tinggi. Pada manajemen sprint, responden sudah memahami fungsinya yaitu untuk memonitor dan mengelola kemajuan sprint serta dapat mencegah kurangnya umpan balik tepat waktu. Berkaitan dengan resistensi terhadap perubahan, responden tidak resisten dengan adanya perubahan yang ada di organisasi. Responden lebih melihat manfaat belajar Scrum dibandingkan metodologi waterfall dan menyatakan bahwa Scrum bukanlah menjadi faktor yang menghambat pekerjaan yang dilakukan responden.

c. Faktor organisasi

Dari delapan variabel pada faktor organisasi, nilai rata-rata yang diperoleh variabel kolaborasi dan pelatihan sudah berada di atas 4,00 yaitu kolaborasi sebesar 4,41 dan pelatihan sebesar 4,11, sementara pada enam variabel lainnya masih di bawah 4,00 . Variabel struktur organisasi memperoleh nilai terendah. Variabel ini difokuskan pada bagaimana dukungan struktur organisasi memungkinkan dalam penggunaan metode Agile secara efektif. Sementara itu pada variabel budaya organisasi, penilaiannya yaitu terkait pengetahuan responden diizinkan ikut serta dalam pengambilan keputusan di organisasi. Pada variabel dukungan organisasi, responden dihadapkan pada pertanyaan seputar persetujuan manajemen untuk adopsi Scrum, manajemen memperkenalkan Scrum kepada seluruh karyawan di organisasi, dukungan manajemen untuk mengikuti pelatihan baik dari sisi waktu maupun pendanaannya, serta manajemen memberikan akses yang mudah kepada orang yang memiliki keahlian yang diperlukan.

d. Faktor teknologi 
Dari tiga variabel pada faktor teknologi, nilai yang diperoleh ketiga variabel tersebut berada di bawah 4,00. Ketiga variabel tersebut perlu mendapat perhatian dalam adopsi Agile di perguruan tinggi. Variabel keuntungan relatif berkaitan dengan sejauh mana Agile telah berkontribusi positif terhadap kondisi dari individu dan organisasi. Berdasarkan hasil wawancara, responden menyatakan bahwa Scrum sesuai dengan pekerjaan yang memerlukan penyelesaian dalam waktu yang cepat sebagaimana keinginan stakeholders dan ini yang menjadi motivasi bagi tim pengembang untuk menggunakan Scrum.

Variabel kompleksitas didefinisikan sebagai tingkat kesulitan yang dialami oleh individu dan organisasi dalam mengadopsi Scrum. Tingkat kesulitan dari individu dalam adopsi Scrum yaitu berkaitan dengan beradaptasi dari sisi kecepatan, manajemen waktu terkait sprint, dan kendala budaya. Sedangkan variabel kompatibilitas merupakan kesesuaian Scrum terhadap nilai-nilai yang ada di perusahaan.

\section{Identifikasi Tantangan}

Penelitian ini telah mengindentifikasi tantangan yang dihadapi dalam melakukan adopsi Agile dengan menggunakan teori SACDM. Berdasarkan nilai rata-rata yang diperoleh dari sembilan belas variabel pada empat konstruk sebagaimana TABEL III, maka untuk memudahkan dalam melakukan analisis, variabelvariabel tersebut dimasukkan ke dalam kelompok tantangan. Kelompok tantangan ini dibuat dalam empat level dengan mempertimbangkan penilaian pada kuesioner yaitu 1,00-5,00, sehingga diambil nilai tengah dari 1,00-5,00 adalah 3,00. Pada kelompok Level 3 (L3) nilai rata-ratanya yaitu 1,00-2,00; kelompok Level 2 (L2) yaitu 2,01-3,00; kelompok Level 1 (L1) yaitu 3,01-4,00 dan kelompok Level 0 (L0) yaitu 4,01-5,00.

Berdasarkan rekapitulasi nilai rata-rata pada semua variabel, maka diperoleh kelompok tantangan sebagaimana Gambar 4. Secara keseluruhan dari sembilan belas variabel tantangan pada empat konstruk pada teori $S A C D M$, tidak ada variabel yang berada di L3 (level terendah), sementara satu variabel yang berada di L2 yaitu pengalaman, 11 variabel berada di L1, dan 7 variabel berada di L0 (variabel didominasi oleh faktor tim sebanyak 5 variabel dan 2 variabel pada faktor organisasi)

Faktor individu: Temuan pada faktor individu yaitu satu variabel berada pada kelompok L2 dan merupakan variabel dengan perolehan nilai rata-rata terendah $(2,90)$ di antara sembilan belas variabel lainnya. Variabel tersebut adalah variabel pengalaman. Organisasi telah menerapkan antisipasi terhadap anggota tim yang kurang pengalaman atas keputusannya merekrut pegawai dari fresh graduate. Komitmen organisasi tersebut terlihat jelas dengan program-program yang dilaksanakan untuk meningkatkan kompetensi dan pengalaman di antara anggota tim. Sedangkan variabel over komitmen dan variabel rekayasa dalam tim berada di kelompok L1. Temuan pada over komitmen di antaranya waktu penyelesaian pada beberapa proyek perangkat lunak telah melewati estimasi yang ditetapkan. Keberlanjutan atas proyek tersebut merupakan kewenangan manajemen dan manajemen akan melakukan analisis SWOT untuk memberikan solusi yang terukur. Sementara itu, temuan pada rekayasa dalam tim yaitu telah terjalin keterlibatan secara langsung antara tim pengembang dengan pengguna baik secara formal maupun informal.

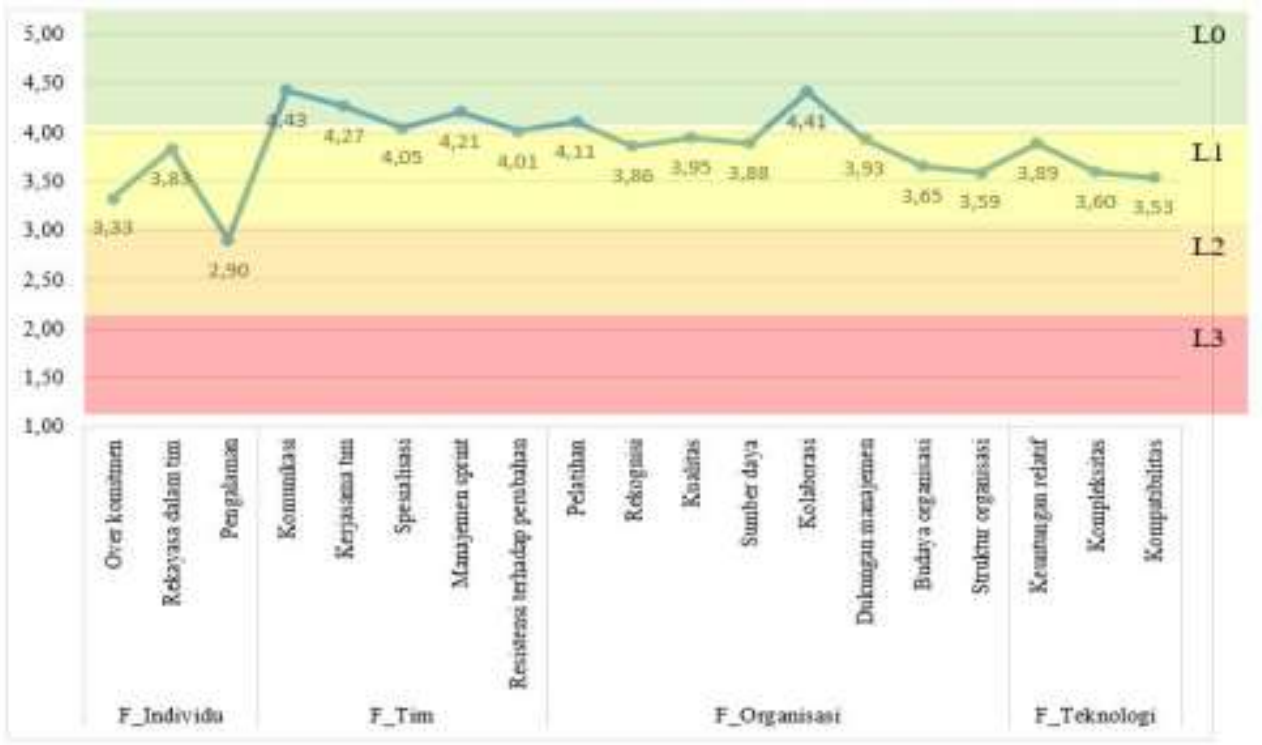

Gambar 4. Kelompok tantangan dalam Adopsi Agile 
Pengalaman merupakan pengetahuan dan keterampilan yang dimiliki anggota tim proyek seperti bahasa pemograman, keterampilan manajemen, dan lain sebagainya yang diperoleh dengan bekerja pada berbagai tugas, proyek, dan tim selama waktu tertentu [20]. Tingkat pengalaman yang tinggi dari manajer proyek tim dan pelatih perangkat lunak yang mengajarkan praktik teknis Agile, memiliki pengaruh pada asimilasi praktik Agile yang cepat dan mendalam [24]. Temuan ini sejalan dengan penelitian pada Entitas Pemerintah di Uni Emirat Arab bahwa salah satu tantangannya yaitu belum ada karyawan yang berpengalaman dengan metode Agile [7].

Sementara itu, over komitmen didefinisikan sebagai terus menugaskan sumber daya untuk proyek-proyek yang menunjukkan tanda-tanda kegagalan [17]. Pemberitahuan yang dilakukan semakin cepat dalam tim Scrum terhadap masalah ini, maka akan semakin besar membatasi pemborosan sumber daya [20]. Sedangkan rekayasa dalam tim yaitu perangkat lunak yang memiliki banyak fitur dan fungsi yang ditambahkan namun tidak diperlukan oleh pelanggan karena kurangnya komunikasi dengan pemangku kepentingan, perencanaan yang buruk atau pengetahuan tim Scrum yang terbatas [19].

1) Faktor tim: Nilai rata-rata yang diperoleh pada faktor tim yang terdiri dari lima variabel telah berada dalam kelompok L0 dengan nilai rata-rata di atas 4,00. Dengan demikian, kelima variabel tersebut telah menunjukkan hasil yang baik. Pada variabel komunikasi yang memperoleh nilai rata-rata tertinggi di antara sembilan belas variabel lainnya telah terkonfirmasi berdasarkan wawancara yang dilakukan dengan responden. Komunikasi telah terjalin dengan baik antar anggota tim dengan berbagai media yang difasilitasi oleh organisasi seperti Slack, Trello, Jira, dan Confluence. Anggota tim telah memaksimalkan Daily Scrum untuk meningkatkan kualitas komunikasi di antara mereka. Organisasi juga telah menyediakan desain tempat kerja yang memudahkan anggota tim untuk saling berkomunikasi secara langsung dan menyampaikan kendala yang dihadapinya.

Komunikasi merupakan salah satu faktor utama untuk kesuksesan produk [12]. Komunikasi dan kolaborasi orang-orang sangat mempengaruhi kualitas Scrum. Anggota tim pengembang adalah ahli lintas fungsi yang memiliki pengalaman yang cukup dalam semua peran teknis. Namun, mereka juga membutuhkan keterampilan sosial yang cukup untuk memfasilitasi komunikasi dan kolaborasi dengan anggota tim lainnya. Dalam kerangka kerja yang berorientasi pada orang, kurangnya kepercayaan di antara anggota tim merupakan hambatan serius untuk komunikasi yang efektif, kolaborasi, dan kinerja tim [25].

Kerjasama tim merupakan suatu proses dimana individu saling bekerja sama sebagai sebuah tim untuk menyelesaikan tugas dan mencapai tujuan bersama [14]. Tantangan dalam kerjasama tim adalah masalah yang berulang, sehingga diperlukan dokumentasi untuk meningkatkan kinerja tim dan organisasi. Sementara, spesialisasi adalah proses seorang individu yang memiliki tingkat pengetahuan dan keterampilan yang tinggi dalam bidang minat, meningkatkan kemahiran, dan keahlian individu dalam perannya [22].

Manajemen sprint adalah aktivitas kotak waktu yang memonitor dan mengelola kemajuan sprint sehingga siklus sprint menjadi optimal [20]. Manajemen sprint diperlukan untuk memonitor dan mengelola kemajuan sprint. Sedangkan resistensi terhadap perubahan adalah proses dalam lingkungan kerja dimana karyawan melihat perubahan sebagai mengganggu dan membosankan [18].

2) Faktor organisasi: Nilai rata-rata yang diperoleh pada faktor organisasi yang terdiri dari delapan variabel, dua variabel berada di kelompok L0 yaitu variabel pelatihan dan kolaborasi. Dengan demikian, pelatihan dan kolaborasi telah menunjukkan hasil yang baik. Sedangkan enam variabel yang lain yaitu rekognisi, kualitas, sumber daya, dukungan manajemen, budaya organisasi, dan struktur organisasi berada dalam kelompok L1 yang mengindikasikan bahwa variabel tersebut perlu mendapat perhatian yang lebih mendalam dari organisasi dibandingkan variabel kelompok L0.

Pelatihan merupakan akuisisi keterampilan dan pengetahuan melalui pengajaran dan pembelajaran untuk meningkatkan bidang kompetensi individu atau kelompok [20]. Dengan mengikuti pelatihan, maka pemahaman tentang Scrum terus meningkat, sedangkan kurangnya pelatihan dapat memicu masalah [23]. Kolaborasi merupakan salah satu nilai yang disebutkan dalam Agile Alliance's Manifesto. Kolaborasi antar pemangku kepentingan sangat penting dalam metode Agile dan merupakan salah satu solusi terhadap masalah yang dihadapi dalam adopsi Agile [18]. Software yang baik dikembangkan sesuai dengan harapan pihak pelanggan sehingga untuk menghindari pengembangan fitur atau sistem yang tidak sesuai dengan permintaan pelanggan, solusinya adalah pengembang harus melibatkan pelanggan untuk berinteraksi [26]. Sejalan dengan itu, Vithana [27] menjelaskan bahwa pelanggan memainkan peran yang sangat penting dalam keberhasilan proyek perangkat lunak dengan perannya sebagai kolaborasi pelanggan, kepuasan pelanggan, dan komitmen pelanggan. 
Rekognisi didefinisikan sebagai pencocokan remunerasi, penghargaan, dan manfaat dengan tingkat produktivitas pekerja [20]. Remunerasi yang sesuai dan reward yang diberikan akan meningkatkan produktivitas karyawan. Individu akan senang dengan pemberian pengakuan atas kontribusi mereka dalam tim. Sementara itu, kualitas didefinisikan sebagai kualitas perangkat lunak yaitu bagaimana proyek perangkat lunak memenuhi kebutuhan bisnis dan harapan pengguna [21]. Sedangkan sumber daya yaitu mengacu pada aset atau layanan seperti staf, bahan, dana, dan lain sebagainya yang mendukung organisasi untuk memproduksi produk dan layanan yang diminta oleh pelanggan [18].

Dukungan manajemen didefinisikan sebagai dukungan yang diberikan oleh organisasi untuk adopsi Scrum [18], [21]. Dukungan manajemen memungkinkan organisasi untuk melihat adopsi inovasi dengan perspektif positif dan menciptakan lingkungan yang kondusif bagi inovasi. Sementara itu, masalah dalam budaya organisasi merupakan tantangan signifikan yang membuat transisi menjadi lebih sulit dari yang diharapkan. Salah satu solusinya adalah fokus pada perilaku organisasi dan memperbaiki budaya organisasi [28]. Struktur organisasi merupakan sistem dengan kegiatan yang ditetapkan yang mengatur individu dalam berperan dan prosedur dikoordinasikan untuk mencapai tujuan organisasi. Organisasi dengan lingkungan yang terbuka dan terintegrasi dengan struktur yang kurang hirarkis meningkatkan adopsi inovasi [20].

3) Faktor teknologi: Nilai rata-rata yang diperoleh pada faktor teknologi yang terdiri dari tiga variabel (keuntungan relatif, kompleksitas, dan kompatibilitas), ketiganya berada di kelompok L1 dengan nilai rata-rata kurang dari 4,00 yang mengindikasikan bahwa variabel tersebut perlu mendapat perhatian yang lebih mendalam di semua variabel tersebut. Temuan pada variabel keuntungan relatif yaitu Scrum sesuai untuk pekerjaan yang perlu diselesaikan dengan cepat dan ini menjadi motivasi bagi tim pengembang untuk menggunakan Scrum. Sementara itu pada variabel kompleksitas ditemukan beberapa kesulitan dari individu dalam adopsi Scrum seperti dalam beradaptasi dengan kecepatan, manajemen waktu sprint, dan kendala budaya.

Keuntungan relatif diukur sejauh mana Scrum telah berkontribusi positif terhadap kondisi dari individu dan organisasi [21]. Sedangkan kompleksitas didefinisikan sebagai tingkat kesulitan yang dialami oleh individu dan organisasi dalam mengadopsi Scrum [14]. Kompatibilitas merupakan kesesuaian Scrum terhadap nilai-nilai yang ada di perusahaan dan individu yang memberikan indikasi bagi individu untuk mengadopsi atau menolak Scrum [20].

\section{PENUTUP}

Berdasarkan referensi penelitian ini, perkembangan tingkat kesuksesan dalam pengembangan perangkat lunak masih rendah. Agile yang merupakan pendekatan relatif baru dalam pengembangan perangkat lunak, semakin banyak diadopsi oleh organisasi terkemuka. Proyek Agile memiliki hampir empat kali tingkat keberhasilannya dibandingkan dengan Waterfall. Agile menjadi semakin populer, sehingga banyak organisasi yang berusaha mengadopsi Agile termasuk perguruan tinggi (UII). Berbagai tantangan ditemukan dalam melakukan adopsi Agile dengan variasi yang berbeda di setiap organisasi. Tantangan adopsi Agile di perguruan tinggi di Indonesia berdasarkan temuan penelitian ini adalah tantangan yang termasuk dalam kelompok L1 dan L2 yaitu: (1) Faktor individu meliputi over komitmen, rekayasa dalam tim, dan pengalaman; (2) Faktor organisasi meliputi rekognisi, kualitas, sumber daya, dukungan manajemen, budaya organisasi, dan struktur organisasi; (3) Faktor teknologi meliputi keuntungan relatif, kompleksitas, dan kompatibilitas. Temuan penelitian ini dapat dijadikan referensi bagi institusi pendidikan atau organisasi lain yang akan melakukan adopsi Agile di institusi masing-masing. Organisasi perlu mempersiapkannya secara matang dan memperhatikan empat konstruk berikut yaitu faktor individu, faktor tim, faktor organisasi, dan faktor teknologi, serta siap mengantisipasi tantangan yang kemungkinan muncul dalam adopsi Agile.

\section{DAFTAR PUSTAKA}

[1] R. Heeks, "Summary for Policymakers," Clim. Chang. 2013 - Phys. Sci. Basis, no. 14, pp. 1-30, 2003.

[2] I. The Standish Group International, "Extreme chaos," 2001. [Online]. Available: https://www.cin.ufpe.br/ gmp/docs/papers/extreme_cha os2001.pdf. [Accessed: 02-Jul-2019].

[3] I. The Standish Group International, "CHAOS REPORT 2015," 2015. [Online]. Available: https://www.standishgroup.com/sample_research_files/ CHAOSReport2015-Final.pdf. [Accessed: 03-Jul-2019].

[4] N. Joseph, "A predictive model for information technology project success," 2013. [Online]. Available: https://ujcontent.uj.ac.za/vital/access/services/Download /uj:10916/CONTENT1. [Accessed: 13-Jun-2019].

[5] R. D. Apriyanto and H. P. Putro, "Tingkat Kegagalan dan Keberhasilan Proyek Sistem Informasi Di Indonesia," Semin. Nas. Teknol. Inf. dan Komun. 2018 (SENTIKA 2018), vol. 2018, no. Sentika, pp. 23-24, 2018.

[6] Agile Alliance, “Agile 101." [Online]. Available: https://www.agilealliance.org/agile101/. [Accessed: 16May-2019]. 
[7] H. Hajjdiab and Al Shaima Taleb, "Adopting Agile Software Development: Issues and Challenges," Int. J. Manag. Value Supply Chain., 2011.

[8] G. S. and A. Sidky, "Becoming Agile: ...in an imperfect world," Manning Publ., 2009.

[9] G. Benefield, "Rolling out agile in a large enterprise," 41st Hawaii Int. Conf. Syst. Sci. IEEE Comput. Soc., 2008.

[10] P. Serrador and J. K. Pinto, "Does Agile work? - A quantitative analysis of agile project success," Int. J. Proj. Manag., vol. 33, no. 5, pp. 1040-1051, 2015.

[11] E. Hajrizi and F. Bytyci, "Agile Software Development Process at Financial Institution in Kosovo," IFACPapersOnLine, 2015.

[12] L. S. dos Santos, A. L'Erario, T. Pagotto, J. R. M. Camilo, F. S. Oliveira, and J. A. Fabri, "A scrum-based process to distributed projects in multidisciplinary teams," in Proceedings of the 13th Conference on Global Software Engineering - ICGSE '18, 2018.

[13] A. Atlas, "Accidental adoption: The story of scrum at amazon.com," in Proceedings - 2009 Agile Conference, AGILE 2009, 2009.

[14] F. Sultan and L. Chan, "Adoption of new technology: The case of object-oriented computing in software companies," HPAC Heating, Piping, Air Cond., vol. 72, no. 2, pp. 106-126, 2000.

[15] J. McKinlay and V. Williamson, "Ten critical HR issues within libraries," Art People Manag. Libr., pp. 191-274, 2010.

[16] I. Ghozali, Aplikasi Analisis Multivariate dengan Program IBM SPSS 19, 5th ed. Semarang: Badan Penerbit Universitas Diponegoro, 2011.

[17] V. G. Stray, "An Empirical Investigation of the Daily Stand-Up Meeting in Agile Software Development Projects," J. Syst. Softw. o, no. September, 2015.

[18] N. Noruwana and M. Tanner, "Understanding the structured processes followed by organisations prior to engaging in agile processes: A South African Perspective," Res. Artic., no. 48, 2012.
[19] R. Santos, F. Flentge, M. E. Begin, and V. Navarro, "Agile technical management of industrial contracts: Scrum development of ground segment software at the european space agency," Lect. Notes Bus. Inf. Process., vol. 77 LNBIP, pp. 290-305, 2011.

[20] R. Hanslo and P. E. Mnkandla, "Scrum Adoption Challenges Detection Model: SACDM," in Proceedings of the 2018 Federated Conference on Computer Science and Information Systems, FedCSIS 2018, 2018, pp. 949957.

[21] M. Devi and V. Senapathi, "Understanding Sustained Usage of Agile Methodologies," 2015. [Online]. Available: $\quad$ http://researchspace.auckland.ac.nz. [Accessed: 15-Jun-2019].

[22] T. E. Fægri, "Adoption of team estimation in a specialist organizational environment," Lect. Notes Bus. Inf. Process., vol. 48 LNBIP, no. 7465, pp. 28-42, 2010.

[23] N. Khan, "SCRUM Adoption: A Solution to Backlog Problems," 2016. [Online]. Available: https://www.researchgate.net/publication/309734111. [Accessed: 09-Jul-2019].

[24] M. Senapathi and A. Srinivasan, "Understanding postadoptive agile usage: An exploratory cross-case analysis," J. Syst. Softw., vol. 85, no. 6, pp. 1255-1268, 2012.

[25] M. N. Sarpiri and T. J. Gandomani, "The Impact of Team Climate on Failure and Success of Scrum Adoption," Int. J. Softw. Eng. Appl., vol. 8, no. 3, pp. 33-38, 2017.

[26] K. S. Haryana, "Penerapan Agile Development Methods Dengan Framework Scrum pada Perancangan Perangkat Lunak Kehadiran Rapat Umum Berbasis QR-Code," Comput. Bisnis, vol. 13, no. 2, pp. 70-79, 2019.

[27] V. N. Vithana, S. G. S. Fernando, and M. Kapurubandara, "Success Factors for Agile Software Development - A Case Study from Sri Lanka," Int. J. Comput. Appl., vol. 113, no. 17, pp. 975-8887, 2015.

[28] T. Javdani Gandomani and M. Ziaei Nafchi, "Agile transition and adoption human-related challenges and issues: A Grounded Theory approach," Comput. Human Behav., vol. 62, pp. 257-266, 2016. 